\title{
Enantioseparation of Racemic 1,1'-Binaphthyl-2,2'-diamine by Preparative Liquid Chromatography
}

\author{
Jae Jeong Ryoo, Woo Jeong Kwon, Tae Hyuk Kim, Kwang-Pill Lee, and Seong-Ho Choi ${ }^{\dagger}$ \\ Dept of Chemistrv, Graduate School, Kungpook National Cniversity, Daegu 702-701. Korea \\ ${ }^{\dagger}$ Dept. of Chemistry, Hamam Lniversity. Daejeon 306-791. Korea \\ Received April 14, 2004
}

\begin{abstract}
The same kind of chiral stationary phase with a commercialized chiral column was used to make preparative chiral columns and was applied to resolve racemic $N$-acetyl-l-naphthỵlethylamide (3) by preparative liquid chromatography. An improved chromatographic condition to resolve racemic 3 on the CSP was examined by changing flow rate and kind of the mobile phase and the sample injection volume. The optimized separation conditions were applied to resolve racemic 1, I'-binaphthyl-2,2'-diamine (4).
\end{abstract}

Key Words : Preparative liquid chromatography, Chiral separation. N-Acetyl-1-naphthylethylanuide. 1,1'-Binaphthy 1-2.2'-diamine. Separation condition

\section{Introduction}

The main purpose of preparative cliromatograply is to offer separation and purification of the samples. Verzele and Bidlingmeyer developed many preparative chromatographic techniques related to column size and mobile phase speed for good resolution. ${ }^{1 . \hat{3}}$ Unger also tried sinilar research with Verzele and Bidlingmeyer and found that columm size and flow rate of the mobile phase deeply affected the resolution on preparative chromatography. Guiochon studied the effect of the antount of a sample injection on the preparative cluromatography, and found the amount was very important to the large scale resolution. ${ }^{6}$ Research related to preparative cluromatography parameters such as. size of column, choice of stationary and mobile phase, column packing density and particle size of stationary phase has been carried out. ${ }^{7}$ The applications. however, are fairly limited due to the kinds and properties of analytes and stationary phase until now.

As the importance of the optically pure compound increased, ${ }^{8}$ the importance of the large scale separation of chiral materials also increased. Many researches related to resolution of racenic compounds by prep. LC has been reported. ${ }^{9.13}$ Polysaccharides cellulose and anylose based prep. colununs developed by Okamoto are most widely used in the world and have been applied to resolve various chiral compounds. ${ }^{14,15}$ These stationary phases were also applied to separate and purify chiral foods. drugs, agricultural chemicals and many inportant chemicals by a SMB (simulated moving bed) method. ${ }^{16}$ Pirkle-type chiral stationary phases are also used as a large scale separation. ${ }^{17}$

In this study, the same kind of chiral stationary phase ${ }^{18}$ with a conmercialized chiral column ${ }^{19}$ (CSP l) was used to make preparative chiral columns. The preparative chiral stationary phase was largely prepared by a very sumilar synthetic procedure with CSP I and was packed into four 7.8 mm ID (inner dianteter) and 250 num length empty columns under different packing pressures, 2000, 4000. 6000 and $8000 \mathrm{psi}$ in order to fund the optinum packing condition.
Since the 8000 psi was the most suitable packing pressure. a $10 \mathrm{~mm}$ ID and $250 \mathrm{~mm}$ length preparative chiral column was additionally prepared under 8000 psi. A preparative liquid cluromatography (prep. LC) experiment was performed to get the optimum analysis conditions by using the prep. colunus. To check the influence of the flow rate of the mobile phase and the sample injection volume of racemic $N$ acetyl-1-naphthyletlyy lamide (3) on the prep LC separation, the flow rate was varied from 4,6 and $8 \mathrm{~mL} / \mathrm{min}$ and the injection volume of a $10 \%$ (w/w) solution of 3 by $0.2,0.4$, 0.6 and $0.8 \mathrm{~mL}$. The racemic 3 was used as a testing analyte of CSP 1 in previous analytical HPLC. ${ }^{18}$ From comparing the results of each condition. the optimum condition was found. This condition was applied to the resolution of racemic 1, l'-binaphthyl-2.2'-diamine (4) which is used as an important starting material for asymmetric synthesis and chiral separation.

\section{Experimental Section}

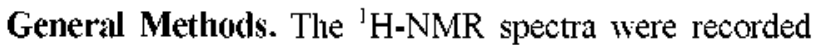
on to a Varian Unity Inova $300 \mathrm{WB}$ Spectrometer $(300 \mathrm{Mz})$. The IR spectra were measured with a Mattson Galasy 7020 Polaris FT-IR Spectrometer. The melting points were taken on a capillary melting point apparatus. Elemental analysis data were obtained with a Carlo Erba EA 1108 Elemental Analyzer.

The reagents used in this study were purchased from the Aldrich Chemical Co. Test racemic materials were prepared according to the procedure described previously ${ }^{i j}$ The solvents for the HPLC analy sis were of Merck HPLC grade. All reactions were performed under a nitrogen atmosphere.

Preparation of Preparative CSP 1. The synthetic method of the preparative CSP I was very similar to that of the analytical CSP $1^{18}$ except for size of silica gel and the amount of chemical used. The commercialized CSP is produced by KMAC with the name of CHIRALRYOO-PGO-1. ${ }^{19}$ The synthesis of N-3,5-dinitrobenzoyl-(R)-phenylglycinol (1) 


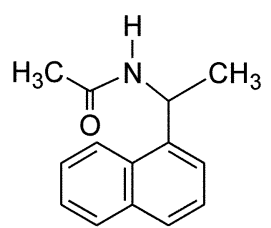

3<smiles>Nc1ccc2ccccc2c1-c1c(N)ccc2ccccc12</smiles>

4<smiles>CCO[Si](C)(C)O[C@H]1C[C@@H](C)O[Si](C)(OCC)O1</smiles>

CSP 1

Figure 1. Structures of racomic samples ( $\mathrm{Y}$-acetyl-I-naphthylethy lamide (3). 1.1-binaphthyl-2.2-diamine (4) and the chiral stationary phase (CSP I) used in the study.

and (R)-N-(3.5-dinitrobenzoyl)phenylglycinol (triethoxysilyl) propylcarbamate (2) could be found in the previous work. ${ }^{\text {is }}$

CSP 1. The $80.0 \mathrm{~g}$ of $10 \mu \mathrm{m}$ Kromasil silica gel (100 $\dot{A})$ and $500 \mathrm{~mL}$, toluene were added to a $1000 \mathrm{~mL}$, round bottom flask. From the resulting slurry, water was removed azeotropically by using a Dean-Stark trap with reflux for 24 hrs. After the water was completely removed, the silyl compound (2) (20.0 g, 34.6 mmole) was added to the slurry solution and the whole mixture was heated to reflux for 80 hrs and stirred mechanically instead of by a spin bar. The reaction flask was cooled to room temperature under nitrogen atmosphere, then the modified silica gel was washed with benzene, methanol, acetone, ethyl acetate, methylene chloride and hexane and dried. The dried silica gel was packed into a $250 \mathrm{~mm}$ length, $10 \mathrm{~mm}$ I.D and four $250 \mathrm{~mm}$ length, $7.8 \mathrm{~mm}$ I.D stainless steel columns under different pressure. The methyl alcohol was used as a packing solvent and the packing time of each column was about 20 minutes.

Preparative Chromatography. The prep. HPI.C system consisting of a Waters Prep I.C controller, Waters 2487 Dual $\lambda$ Absorbance Detector (254 nm UV filter), and Waters Delta Prep 4000 preparative chronatography system was controlled by Win 98 Millennium 32 program. All chromatographic data were obtained using 2-propanol/hexane $(20: 80)$ as a mobile phase and the column void volume was checked by injecting 1,3,5-tri-tert-butylbenzene, a presumed unretained solute ${ }^{21}$ which was obtained from the Aldrich Chemical Co. Three grams of $N$-acetyl-1-naphthylethylamide (3) were synthesized by a known method, ${ }^{20}$ and 1,1-binaphthyl-2,2'diamine (4) was obtained from the Aldrich Chemical Co. The structures of the two samples are shown in Figure 1. The sample solutions were prepared by dilution of $1.00 \mathrm{~g}$ of 3 or $0.80 \mathrm{~g}$ of 4 with $10 \mathrm{~mL}$ methanol. The flow rate of the mobile phase was varied from 4,6 , and $8 \mathrm{~mL} / \mathrm{min}$ and the injection volume of a $10 \%(\mathrm{w} / \mathrm{v})$ solution of racemic $N$ acetyl-1-naphthylethylamide (3) by $0.2,0.4,0.6$, and that of a $8 \%(w / v)$ solution of racemic $1,1^{\prime}$-binaphthyl-2,2'-diamine (4) by $0.1,0.2,0.5$, and $0.8 \mathrm{ml}$.

\section{Results and Discussion}

Preparation of a Preparative Chiral Stationary Phase (CSP 1). A commercialized CSP developed by our laboratory was prepared in bulk (about $80 \mathrm{~g}$ ) with some modifications in order to obtain a preparative separation of racemic 3 and 4 . Fach synthetic step is quite simple and easy, but, in the last step, connecting the silyl compound (2) to $80.0 \mathrm{~g}$ of $10 \mu \mathrm{m}$ Kromasil silica gel had to be done using a mechanical stirrer instead of a magnetic stirrer because the silica gel was broken by a spin bar in the course of magnetic stirring. From the elemental analysis result of the bonded silica gel (Anal, found $\left(\mathrm{C}_{21} \mathrm{H}_{25} \mathrm{~N}_{1}\right): \mathrm{C}, 3.81 ; \mathrm{N}, 0.92$. Calcd, 0.15 mmole/g (based on C), 0.14 mmole/g (based on N)), it was calculated that the average amount of chiral selector bonded to the silica gel was about 0.15 mmole per $1 \mathrm{~g}$ of silica gel. The bonded chiral stationary phase was packed into four $250 \mathrm{~mm}$ length, $7.8 \mathrm{~mm}$ 1.D stainless steel columns under $2000,4000,6000$ and 8000 psi and the preparative chiral columns were tested by sample 3 .

As shown in Table 1 , as the packing pressure of the column increased, the resolution and number of theoretical plate increased continuously but the operating pressure of the system also largely increased. In such a situation. the packing pressure did not exceed 8000 psi. From these results, a $250 \mathrm{~mm}$ length $10 \mathrm{~mm}$ l.D stainless steel column was packed under 8000 psi and the preparative chiral column was also tested by sample 3 and the results are shown in the right end column of lable 1 . A comparison between the different sized columns packed under the same

Table 1. Resolution of racemie N-acetyl-I-naphthylethylamide (3) on tive different preparative columns ${ }^{4}$

\begin{tabular}{|c|c|c|c|c|c|}
\hline \multirow{3}{*}{$\begin{array}{l}\text { Column size } \\
\text { Packing pressure }\end{array}$} & \multicolumn{4}{|c|}{$7.8 \mathrm{~mm} \mathrm{ID} \times 250 \mathrm{~mm}$ length } & \multirow{3}{*}{$\begin{array}{c}10 \mathrm{~mm} \times 250 \mathrm{~mm} \\
8000 \\
\mathrm{psi}\end{array}$} \\
\hline & 2000 & 4000 & 6000 & 8000 & \\
\hline & psi & $\mathrm{psi}$ & psi & psi & \\
\hline $\mathrm{N}^{2} / 1 \mathrm{~m}$ & 14600 & 16200 & 24300 & 26800 & 36800 \\
\hline operating pressure (psi) & 906 & 912 & 927 & 1008 & 786 \\
\hline$\alpha$ & 1.52 & 1.47 & 1.53 & 1.50 & 1.51 \\
\hline Rs & 1.26 & 1.41 & 1.64 & 1.73 & 1.79 \\
\hline
\end{tabular}

"Flow ratc: $6 \mathrm{~mL}$ imin. injection volume; $0.2 \mathrm{ml}$.. mobile plase: $20 \%$ IPA in hexane. "Number of theoretical plate ( $N$ im) 


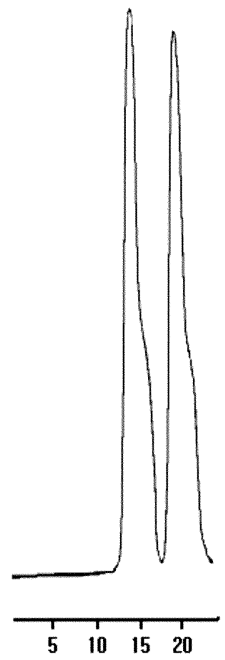

(a)

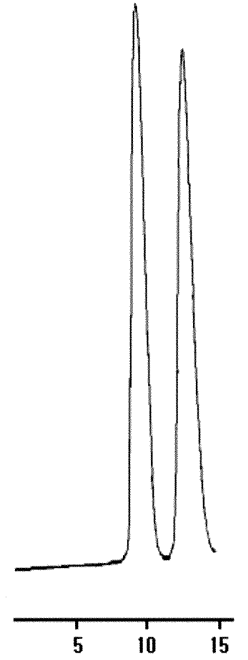

(b)

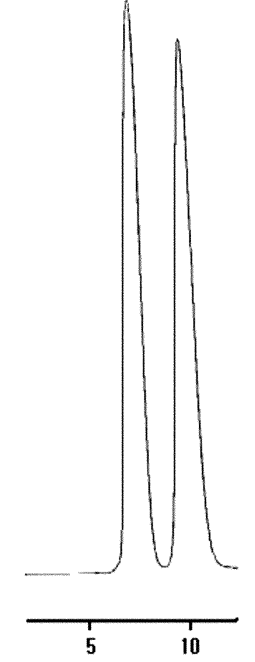

(c)

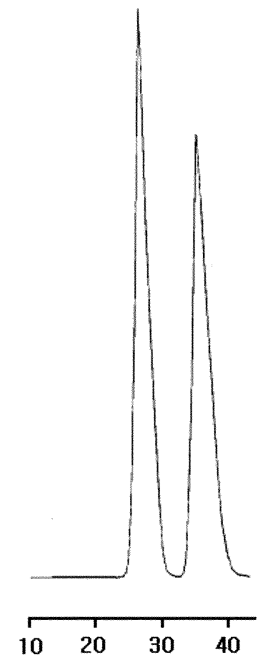

(d)

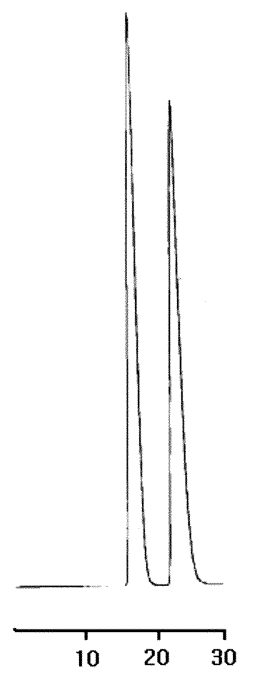

(e)

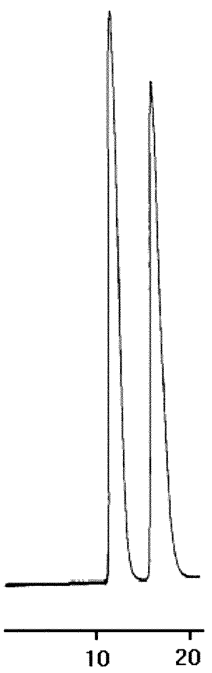

(f)

Figure 2. Chromatograms of the separation of racemic 1 -acetyl-1-naphthylothylamide (3) on preparative CSP I at different flow rates (l/R). Mobilc phase; $20 \% 2$-propanol in hexanc. Sample injection volume $(\mathrm{V} / \mathrm{V}) ; 0.2 \mathrm{~mL}(20 \mathrm{mg}$ ) (a) column size; $7.8 \mathrm{~mm} \mathrm{ID} \times 250 \mathrm{~mm}$ length. F/ R $4 \mathrm{~mL} / \mathrm{min}$. (b) F/R $6 \mathrm{~mL} / \mathrm{min}$. (c) F/R $8 \mathrm{~mL} / \mathrm{min}$. (d) colums size: $10 \mathrm{~mm} \mathrm{ID} \times 250 \mathrm{~mm}$ length. F/R $4 \mathrm{~mL} / \mathrm{min}$. (e) F/R $6 \mathrm{ml} / \mathrm{min}$. (1) F/R $8 \mathrm{ml} \min$.

8000 psi showed that a small operating pressure, an improved resolution $(R s)$, and a high number of theoretical plates $(N)$ were found in the larger column. Therefore, the 250 $\mathrm{mm}$ length, $10 \mathrm{~mm}$ l.D chiral preparative column packed under 8000 psi was mainly used in this study as CSP 1 .

Determination of an Optimum Flow Rate of Mobile Phase in Preparative Chromatography. To determine the optimum flow rate for the preparative separation of racemic $N$-acetyl-1-naphthylethylamide (3) on the two different sized CSP 1, preparative chiral chromatographic experiments were performed by changing the flow rate of the mobile phase with the following rates, 4,6 and $8 \mathrm{~mL} / \mathrm{min}$.

In Figure 2, the elution rate was about twice as fast in the small sized column (elution time; 2(a)-24 min, 2(d)-40 min and 2 (c)-12 $\mathrm{min}, 2(\mathrm{f})-20 \mathrm{~min}$ ), but the resolution was better in the larger column. A comparison of the inner volume between the two columns showed that the larger one was twice that of the smaller one. The larger columns empty volume was about 20 $\mathrm{cm}^{3}\left(\pi \times(0.5 \mathrm{~cm})^{2} \times 25 \mathrm{~cm}=19.63 \mathrm{~cm}^{3}\right)$, on the other hand, the smaller column was about $12 \mathrm{~cm}^{3}\left(\pi \times(0.39 \mathrm{~cm})^{2} \times 25 \mathrm{~cm}\right.$ $\left.=11.94 \mathrm{~cm}^{3}\right)$. In addition, the packing capacity of the general packed column is $60 \%\left(\varepsilon_{7}: 0.4\right),^{22}$ the empty volume of the larger packed column is about $7.85 \mathrm{~cm}^{3}(0.4 \times 19.63=7.85$ $\left.\mathrm{cm}^{3}\right)$, whereas that of the sinaller one is about $4.78 \mathrm{~cm}^{3}$
Table 2. Resolution of racemic $\mathrm{N}$-acetyl-1-naphthylethylamide (3) on preparative CSP 1 at different flow rate"

\begin{tabular}{|c|c|c|c|c|c|c|c|c|}
\hline \multirow{2}{*}{$\begin{array}{l}\text { Flow-rale } \\
\text { (truLinin) }\end{array}$} & \multicolumn{4}{|c|}{$7.8 \mathrm{~mm} \mathrm{II)}$} & \multicolumn{4}{|c|}{$10 \mathrm{~mm} \mathrm{IIJ}$} \\
\hline & $k_{1}$ & $\alpha x$ & Rs & $\begin{array}{l}\text { operating } \\
\text { pressure }\end{array}$ & $k_{1}$ & $\alpha$ & Rs & $\begin{array}{l}\text { operating } \\
\text { pressure }\end{array}$ \\
\hline 4 & $\begin{array}{r}10.0 \\
3\end{array}$ & 1.48 & 1.18 & 858 & 17.0 & 1.49 & 1.47 & 696 \\
\hline 6 & 7.19 & 1.49 & 1.73 & 1008 & 10.0 & 1.51 & 1.79 & 786 \\
\hline 8 & 5.41 & 1.48 & 1.57 & 1122 & 7.85 & 1.50 & 1.71 & 882 \\
\hline
\end{tabular}

"Sample injection volume; $0.2 \mathrm{mI}$. (20 mg). mobile phase: $20 \% \mathrm{PA}$ in hexane.

$\left(0.41 \times 1.94=4.78 \mathrm{~cm}^{3}\right)$. Therefore, the elution rate was small in larger one and it was in accordance with the chromatographic results.

The actual operating pressure and some chromatographic parameters calculated from the chromatograms in Figure 2 were arranged in lable 2 . When the same amount ( $20 \mathrm{mg}$ ) of samples were introduced to the two columns, it was observed that as the flow rate of the mobile phase increased. the selectivity factor (a) was not influenced but the resolution (Rs) values changed. Also, the operating pressure of the LC system increased and the retention factor

Table 3. Relation between sample injection volume and the resolution (Rs) in the enantioseparation of racemic $\mathrm{V}$-acetyl-Inaphthylethylamide (3) on preparative CSP 1 "

\begin{tabular}{|c|c|c|c|c|c|c|c|c|c|c|c|c|}
\hline \multirow{3}{*}{$\begin{array}{l}\text { Flow rate } \\
\text { (ml irin) }\end{array}$} & \multicolumn{12}{|c|}{ Inịection volume (Amount of sample 3 ) } \\
\hline & \multicolumn{3}{|c|}{$0.2 \mathrm{~mL}(20 \mathrm{mg})$} & \multicolumn{3}{|c|}{$0.4 \mathrm{~mL}(40 \mathrm{mg})$} & \multicolumn{3}{|c|}{$0.6 \mathrm{~mL}(60 \mathrm{mg})$} & \multicolumn{3}{|c|}{$0.8 \mathrm{~mL}(80 \mathrm{mg})$} \\
\hline & $k_{1}$ & $\alpha$ & Rs & $k_{1}$ & $\gamma$ & $\mathrm{Rs}$ & $h_{1}$ & $\alpha$ & Rs & $k_{l}$ & $\alpha$ & Rs \\
\hline 4 & 17.0 & 1.49 & 1.47 & 16.0 & 1.51 & 0.81 & 15.1 & 1.50 & 0.62 & 14.7 & 1.49 & 0.49 \\
\hline 6 & 100 & 1.52 & 1.79 & 9.4 & 1.51 & 1.05 & 9.4 & 1.52 & 0.83 & 10.2 & 1.51 & 0.55 \\
\hline 8 & 7.85 & 1.50 & 1.71 & 7.45 & 1.49 & 0.97 & 7.45 & 1.49 & 0.83 & 7.65 & 1.51 & 0.55 \\
\hline
\end{tabular}

"Mobile plase: 20\% IPA in lievane. 
Table 4 . Relation between sample injection volume and the resolution (Rs) in the enantioseparation of racemic 1,1 -binaphthy l-2,2'-diamine (4) on preparative CSP $1^{a}$

\begin{tabular}{|c|c|c|c|c|c|c|c|}
\hline $\begin{array}{l}\text { Injection volume } \\
\text { (Amount of sample } 4 \text { ) }\end{array}$ & $\begin{array}{c}0.2 \mathrm{~mL} \\
(16 \mathrm{mg})\end{array}$ & $\begin{array}{c}0.1 \mathrm{~mL} \\
(8.0 \mathrm{mng})\end{array}$ & $\begin{array}{l}0.05 \mathrm{~mL} \\
(4.0 \mathrm{mg})\end{array}$ & $\begin{array}{l}0.02 \mathrm{~mL} \\
(1.6 \mathrm{mg})\end{array}$ & $\begin{array}{l}0.01 \mathrm{~mL} \\
(0.8 \mathrm{mg})\end{array}$ & $\begin{array}{c}5 \mu \mathrm{L} \\
(0.4 \mathrm{mg})\end{array}$ & $\begin{array}{c}2.5 \mu \mathrm{L} \\
(0.2 \mathrm{mg})\end{array}$ \\
\hline $\mathrm{Rs}$ & 0 & 0.41 & 0.46 & 0.53 & 0.62 & 0.63 & 0.61 \\
\hline
\end{tabular}

"Mobile phase: $20^{\circ} .0$ IPA in hexane, flow rate: $6 \mathrm{~mL}$ min.

decreased continuously. The best resolution appeared when the flow rate of the mobile phase was $6 \mathrm{~mL} / \mathrm{min}$. When the mobile phase speed was $+\mathrm{mL} / \mathrm{min}$ in the smaller sized column (Figure 2(a)). the resolution was at its worst and the shoulder peak appeared every time. The bad resolution at 4 $\mathrm{mL} / \mathrm{min}$ may be a result from the band broadening effect caused by the relatively low speed. but reasons for the distorted peak are not known

A comparison of the two different sized columns in the separation of racemic 3 showed the larger (10 mum ID) column with good resolution in a low operating pressure. It was thought that there were many chiral selectors which could interact with analytes in the larger colunun.

Determination of an Optimum Sample Injection Volume in Preparative Chromatography. To determine the optimum sample injection volume for the preparative separation of racemic $N$-acetyl-1-naphthy lethylamide (3) on CSP 1. preparative chiral chromatographic experiments were performed by changing the sample injection volume using the following: $0.2 \mathrm{~mL}(20 \mathrm{mg}), 0.4 \mathrm{~mL}(40 \mathrm{mg}) .0 .6 \mathrm{~mL}(60$ $\mathrm{mg}$ ) and $0.8 \mathrm{~mL}(80 \mathrm{mg})$ while retaining the same mobile phase speed. $6 \mathrm{~mL} / \mathrm{min}$. The results were summarized in Table 3 .

The resolution (Rs) of the $40 \mathrm{mg}$ injection sample at $6 \mathrm{~mL} /$ min was 1.05 and that of the $20 \mathrm{mg}$ injection sample at the same flow rate was 1.79. In addition, the resolution (Rs) improved from 0.80 to 1.47 when the injection volume of the sample decreased from $0.4 \mathrm{~mL}(40 \mathrm{mg})$ to $0.2 \mathrm{~mL}(20 \mathrm{mg})$ at a mobile phase speed of $4 \mathrm{~mL} / \mathrm{min}$. The same phenomena was also found at $8 \mathrm{~mL} / \mathrm{min}$. Therefore. the sample injection volumes are limited in the preparative separation. In this case. the selectivity factor for the enantioseparation of racenic $N$-acetyl-1-naphthylethylamide (3) on CSP I was about 1.5 . The sample 3 could be effectively separated if 20 $40 \mathrm{mg}$ samples were injected at once on a $10 \mathrm{~mm}$ ID, 250 $\mathrm{mm}$ length preparative columm. On the other hand. the resolution values (Rs) were similar to each other between mobile phase speeds of $6 \mathrm{~mL} / \mathrm{min}$ and $8 \mathrm{~mL} / \mathrm{min}$. It is thought that $8 \mathrm{~mL} / \mathrm{min}$ is more useful than $6 \mathrm{~mL} / \mathrm{min}$ from a practical point of view.

Resolution of Racemic 1,1'-Binaphthyl-2,2'-diamine (4) on Preparative CSP 1. The application of the optimum conditions to a large scale separation of racenic 1.1'. binaphthyl-2.2'-diamine (t) which is used as a starting material for an asymmetric catalyst ${ }^{33}$ was performed. The selectivity factor $(\alpha)$ for sample + on $4.2 \mathrm{~nm}$ ID. $250 \mathrm{~mm}$ length analytical CSP 1 was about 1.15 , therefore the preparative resolution would be more difficult than sample 3 $(\alpha=1.50)$. The results for the resolution of racemic $t$ on 10 nm ID. $250 \mathrm{~mm}$ length preparative CSP 1 were shown in Table 4

As shown in Table 4. there was no resolution in the case of $16 \mathrm{mg}$ sample injection. However, the best resolution was found when $0.8 \mathrm{mg}$ of 4 was introduced and there was no improvement in the resolution even if it was smaller than the $0.8 \mathrm{mg}$ of sample that was injected.

In conclusion. the preparative chiral cluromatographic experiments were performed with two well known chiral samples, $\quad N$-acetyl-1-naphthylethylamide (3) and 1.1binaphthyl-2,2'-diamine (4) which have low selectivity factors $(\alpha=1.50$ and 1.15$)$ by using CSP 1 . When the size of the column was $10 \mathrm{~mm}$ ID. with a $250 \mathrm{~mm}$ length and the selectivity factor of a sample was about 1.5. the best flow rate of mobile phase was about $8 \mathrm{~mL} / \mathrm{min}$ and optimum injection amount of sample was $20-40 \mathrm{mg}$. While the selectivity factor of a sample was about 1.15 on the same colunn. the optimum flow rate was about $6 \mathrm{~mL} / \mathrm{min}$ and the optimum injection amount of the sample was $0.8 \mathrm{mg}$.

Acknowledgments. This work was supported by a grant (No. 2001-12400-003-1) from the Korea Science \& Engineering Foundation.

\section{References}

1. Verzele, M.: Dewaele. C. Preparative High Perfornance Liquid Chromatograph if practical gatdelme: Eke: Belgium, RSL Europe: 1986: $\mathrm{p} 1$.

2. Verzele. M.: Dewaele. C.: Van Duck. I.: van Haver. D. $J$ Chromatogr: 1982. 249. 231-238.

3. Bidlingmeyer. B. A. Preparative Liquid Chomatograpln: Elsevier: Amsterdam. 1987; p 1.

4. Unger. K. K.: Jauzen. R. J. Chrontatogr. 1986. 373. 227-264.

5. Unger. K. K.: Roumeliotis. P. $J$. Chomatogr. 1979. 185.445-452.

6. (a) Golshan-Shirazi. S.: Guiochon. G. J. Chromatogr: A 1994. 658 . 149-171. (b) Guiochon. G. J. Chomatogr. A 2002.965. 129-161.

7. Heuer. C.: Hugo. P.; Mann, G. J. Chrontatogr d 1996, 752. 19-29.

8. Jacques. J; Collet, A; Wilen, S. H. Enamtioners. Racentates and Resolutions; New York: Wiley Interscience: 1981; p 1.

9. Alcaro. S.: DAcquarica. I.: Gasparrini. F.: Misiti. D.: Pierini. M.: Villani. C. Tetrahedron Asw 2002. 13. 69-75.

10. (a) Francotte. E. R.: Leutert. T.: Vecchia. L. L.: Ossola. F.: Richeıt. P.: Schmidt. A. Chinality 2002, 14,313-317. (b) Francotte. E. R. J. Chrontatogr A 2001, 906, 379-397.

11. Alias. M.; Cativiela. C.: Jimenez. A. I.: Lopez, P.; Oliveros. L.; Marraud. M. Chivality 2001. 13. 48-55.

12. (a) Hostettmann1. K.: Marstonl. A. Praparative Chomatograply, Techniques. 2nd ed: Springer: 1988: p 218. (b) Pisarev. O. A.: Glasova. N. V. J. Chrontatogr. A 2003, 1018. 129-136.

13. Bringezu. F: Dobner. B.: Stritzel. R.: Elsner. B.; Nuhn, P. J. Chronatogr. A 1996, 724. 367-372.

14. Okamoto. Y.: Kaida. Y. J. Chromatog: A 1994. 666.403-419 
15. Miller. L.: Bergeron. R. J. Chomatogr. A 1993. 648. 381-388.

16. (a) Proll. T: Kusters. E. J. Chromatogr: A 1998. 800 . 135-150. (b) Schulte. M.: Strube, J. J. Chrontatogr it 2001, 906. 399416.

17. Pirkle. W. H.: Koscho, M. E. J. Chrontatogr: A 1999, 840, 151158.

18. Ryoo. J. J.: Im. S. H.: Park. J. H.: Hyun. M. H. Mforochemical J. 1999.63.128-133

19. http wwwkmacto:
20. Hyun. M. H.: Kim. M. H. J. Liq. Chomatogr 1990. 13. 3229 . 3243.

21. Pirkle. W. H.: Welch, C. J. J. Liq. Chrontatogr 1991. H, 1-8.

22. (a) Braithwaite. A.: Smith, F. J. Chromatographic Methods, 5th ed: Blackie academic \& professional: 1996; pp 23-24. (b) Subramanian. G. Preparative and Process-scak Liquid Chomatography: Ellis Horwood Limited: 1991: pp 14-24.

23. Guo. R.: Li. X.: Wu. T.: Kwok. W. H.: Chent. J.: Choi. M. C. K.: Chan. A. S. C. Tetrahedron Letters 2002, $13,6803-6806$. 